\title{
Follistatin-like protein 1 plays a tumor suppressor role in clear-cell renal cell carcinoma
}

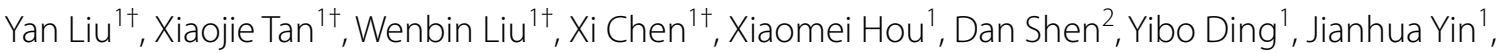 \\ Ling Wang ${ }^{1}$, Hongwei Zhang ${ }^{1}$, Yongwei $\mathrm{Yu}^{3}$, Jianguo Hou${ }^{2}$, Timothy C. Thompson ${ }^{4}$ and Guangwen Cao ${ }^{1 *}$
}

\begin{abstract}
Background: We previously showed that the expression of follistatin-like protein 1 (FSTL1) was significantly downregulated in metastatic clear-cell renal cell carcinoma (ccRCC). In this study, we aimed to characterize the role of FSTL1 in the development of ccRCC.

Methods: The effects of FSTL1 on cell activity and cell cycle were investigated in cCRCC cell lines with altered FSTL1 expression. Gene expression microarray assays were performed to identify the major signaling pathways affected by FSTL1 knockdown. The expression of FSTL1 in CCRCC and its effect on postoperative prognosis were estimated in a cohort with 89 patients.

Results: FSTL1 knockdown promoted anchorage-independent growth, migration, invasion, and cell cycle of ccRCC cell lines, whereas FSTL1 overexpression attenuated cell migration. FSTL1 knockdown up-regulated nuclear factor-kB (NF-KB) and hypoxia-inducible factor (HIF) signaling pathways, increased epithelial-to-mesenchymal transition, upregulated interleukin- 6 expression, and promoted tumor necrosis factor-a-induced degradation of NF-kB inhibitor (IKBa) in ccRCC cell lines. FSTL1 immunostaining was selectively positive in epithelial cytoplasm in the loop of Henle, and positive rate of FSTL1 was significantly lower in CCRCC tissues than in adjacent renal tissues $(P<0.001)$. The multivariate Cox regression analysis showed that the intratumoral FSTL1 expression conferred a favorable independent prognosis with a hazard ratio of 0.325 (95\% confidence interval 0.118-0.894). HIF-2a expression was negatively correlated with FSTL1 expression in CCRCC specimens $(r=-0.229, P=0.044)$. Intratumoral expression of HIF-2a, rather than HIF-1a, significantly predicted an unfavorable prognosis in $\mathrm{CCRCC}$ (log-rank, $P=0.038$ ).
\end{abstract}

Conclusions: FSTL1 plays a tumor suppression role possibly via repressing the NF-KB and HIF-2a signaling pathways. To increase FSTL1 expression might be a candidate therapeutic strategy for metastatic ccRCC.

Keywords: Follistatin-like protein 1, Clear cell renal cell carcinoma, NF-KB, HIF-2a, Prognosis, Tumor suppressor

\section{Background}

Renal cell carcinoma (RCC) is the seventh most common cancer worldwide and the tenth most common cancer in the urban areas of China [1]. Clear cell RCC (ccRCC) is the major histotype, accounting for $80 \%$ of all RCC [2]. Early-stage RCC has an asymptomatic clinical course; $25 \%-30 \%$ of patients appear with metastatic disease [2].

\footnotetext{
*Correspondence: gcao@smmu.edu.cn

†Yan Liu, Xiaojie Tan, Wenbin Liu and Xi Chen contributed equally to this work

1 Department of Epidemiology, Second Military Medical University, Shanghai 200433, P. R. China

Full list of author information is available at the end of the article
}

Approximately $30 \%$ of RCC patients who undergo curable resection of localized tumors eventually develop distant metastases [2]. Metastatic RCC is resistant to routine chemotherapy and radiotherapy. The 5-year survival rate of RCC patients with metastasis was $31.6 \%$ [3]. However, a percentage of metastatic RCC is sensitive to immunotherapy and targeted therapy [4-7]. To improve postoperative survival of RCC patients, it is important to identify the factors that have prognostic or predictive values, thus leading to monitoring for disease recurrence and opportunities for targeted and/or immunotherapy. D9S168 microsatellite alteration in tumors [8], intratumoral neutrophil [9], intratumoral expression of proteins including 
chemokine (C-X-C motif) receptor 8 (CXCR8) [10], CD44 [11], CXCR3, insulin-like growth factor mRNA-binding protein 3, survivin, B7 homolog 1 [12], glycolytic enzymes [13], circulating molecules such as human telomerase reverse transcriptase [14], spermine/spermidine [15], urinary cathepsin D [16], and co-expression of interleukin-6 (IL-6) and its receptor have been associated with poor prognosis in RCC patients [17]. High level of chemokine (C-X-C motif) ligand 16 (CXCL16) expression in tumors is associated with a longer survival [18]. However, more prognostic and/or predictive molecules are needed to optimize postoperative care for RCC patients with different genetic background.

In our previous study investigating global profiling of gene expression in RCC cells with different metastatic potential, we found that follistatin-like protein 1 (FSTL1) was frequently down-regulated in metastatic ccRCC [19]; and the C allele of rs1259293 in the coding region of FSLT1 was associated with an increased risk and unfavorable postoperative prognosis of RCC, possibly by down-regulating FSTL1 expression in renal tissues [20]. FSTL1, a secreted glycoprotein encoded on chromosome 3 in humans, is widely expressed in cells of non-hematopoietic lineage, particularly in cells of the mesenchymal lineage [21]. FSTL1 is induced in response to inflammatory injuries and plays important roles in promoting the accumulation of myofibroblasts and subsequent fibrosis, promoting cardiac function, and reducing glomerular and tubulointerstitial inflammatory damage in the kidney via attenuating tumor necrosis factor alpha (TNF $\alpha$ )stimulated expression of proinflammatory cytokines [22-24]. The role of FSTL1 in cancers is controversial. During cancer metastasis from the primary site to the bone, FSTL1 mediates cancer cell invasion and expands a population of bone marrow-derived pluripotent mesenchymal stem-like cells [25]. In prostate cancer, the androgen-dependent up-regulation of FSTL1 promotes growth of cancer cells [26]. In colorectal cancer (CRC), FSTL1 is selectively expressed in cancer stroma and attenuates CRC cell proliferation [27]. Although FSTL1 is overexpressed in plasma and cancerous tissues of CRC patients, it has not been, thus far, implicated in prognosis [28]. In ovarian and endometrial cancers, FSTL1 functions as a tumor suppressor via inducing apoptosis [29]. However, the role of FSTL1 in RCC remains elusive.

We hypothesized that FISTL1 might play a role as tumor suppressor in ccRCC. In the present study, we aimed to clarify the effects of aberrant FSTL1 expression on the growth and aggressiveness of RCC cells, identify the signaling pathways that were affected by FSTL1, and validate the prognostic functions of FSTL1 with a cohort of RCC patients.

\section{Methods}

Cell culture, plasmid constructs, and transfection

Human ccRCC cell lines ACHN and 786-O were purchased from American Tissue Culture Collection (Manassas, VA, USA), with Accession Numbers CRL1611 and CRL-1932, respectively. Human embryonic kidney (HEK) 293T cells were purchased from the cell bank, Chinese Academy of Sciences (No. CBP60439, Shanghai, China). NRCC (low-metastatic) and MRCC (high-metastatic) ccRCC cell lines were established from two Chinese ccRCC patients in our laboratory [30]. 786-O cells were grown in RPMI-1640 media (Hyclone, Pittsburgh, PA, USA) supplied with $10 \%$ fetal bovine serum (FBS) (GIBCO, Grand Island, NY, USA), 100 U/ $\mathrm{mL}$ penicillin, and $100 \mu \mathrm{g} / \mathrm{mL}$ streptomycin (Invitrogen, Carlsbad, CA, USA). ACHN, MRCC, NRCC, and HEK 293T cells were grown in DMEM (Hyclone) supplied with $10 \% \mathrm{FBS}, 100 \mathrm{U} / \mathrm{mL}$ penicillin, and $100 \mu \mathrm{g} / \mathrm{mL}$ streptomycin.

Two short hairpin RNA (shRNA) targeting the different regions of FSTL1 mRNA (shFSTL1-1 and shFSTL1-2) and a scrambled control (shScramble) were constructed into the pSuper-retro vector (OligoEngine, Seattle, WA, USA) and confirmed by sequencing, respectively. The sequences of the shRNA were 5'-AAGAGAGTGAGCACCAAAGAG-3' (shFSTL1-1), 5'-AAGCATCAGGAAACAGCTGAA-3' (shFSTL1-2), and $5^{\prime}$-CTGGCATCGGTGTGGATGA-3' (shScramble). A full-length human FSTL1 cDNA clone (No. MHS477199611059) was purchased from Thermo Fisher Scientific (Pittsburgh, PA, USA), released by BamHI and XhoI digestion, and inserted into the mammalian expression vector pcDNA3.1/V5-His topo (Invitrogen) to construct a topo-FSTL1 plasmid that could express FSTL1.

The retrovirus packing vector Pegpam $3 \mathrm{e}$ and recombination directionality factor (RDF) vector were kindly provided by Yang [31]. Retroviral supernatants were harvested at $72 \mathrm{~h}$ after HEK $293 \mathrm{~T}$ cells were co-transfected with shRNA plasmids and two packing plasmids by Fugene HD Transfection Reagent (Promega, Madison, WI, USA). NRCC cells were incubated with virus-containing medium supplemented with $4 \mu \mathrm{g} / \mathrm{mL}$ polybrene (Sigma-Aldrich, St. Louis, MO, USA). Stable FSTL1knockdown NRCC cells were selected in the presence of $3.5 \mu \mathrm{g} / \mathrm{mL}$ puromycin (Sigma-Aldrich) for 7 days. Topo-FSTL1 expression plasmid, empty topo vector, shFSTL1-1, shFSTL1-2, and shScramble were transfected using lipofectamine LTX and Plus Reagent (Invitrogen) into 786-O cells and ACHN cells, respectively. FSTL1 mRNA expression was examined by quantitative reverse transcription-polymerase chain reaction (qRT-PCR) and Western blotting. 


\section{Growth, migration, and invasion assays}

Anchorage-independent growth of RCC cells with aberrant FSTL1 expression was evaluated with a double-layered soft agarose culture system, as previously described [30]. Cell migration assay (without matrigel) and cell invasion assay (with matrigel) were performed using $8-\mu \mathrm{m}$ pore size 24-well cell culture transwell plates (Corning, Corning, NY, USA). These experiments were performed in triplicate.

\section{Cytometry}

Cell cycle and cell surface markers of NRCC-shScramble and NRCC-shFSTL1 cells were examined using a flow cytometer (MACSQuant, Miltenyi Biotec, Bergisch Gladbach, Germany). The estimation of cell cycle was performed with propidium iodide (PI) staining as previously described [29]. To compare proportions of cells in different cell cycle phases, NRCC-shFSTL1 and NRCCshScrambled cells were passaged synchronously. Cell markers were detected using anti-CD44-PE (1:10 dilution; Biolegend No. 338808, San Diego, CA, USA), antiCD105-FITC (1:10 dilution; Biolegend No. 323204), anti-CD24-FITC (1:10 dilution; Biolegend No. 311104), anti-CD99-FITC (1:10 dilution; Biolegend No. 318006), anti-CD133-PE (1:10 dilution; Miltenyi No. 00029, Bergisch Gladbach, Germany), anti-vimentin (1:50 dilution; Santa Gruz Biotechnology No. Sc-32322, Santa Gruz, CA, USA), and anti-EpCAM (1:50 dilution; Cell Signaling Technology No. 2929, Danvers, MA, USA) monoclonal antibodies. Cell debris and fixation artifacts were excluded by appropriate gating. The acquisition process was stopped when 10,000 events for cell cycle analysis and 30,000 events for cell surface marker analysis were collected in the population gate. The FlowJo version 7.6 software (Flowjo, Ashland, NC, USA) was used for data acquisition and analysis. Assays for other details were as previously described [30]. Each flow cytometry assay was conducted in triplicate.

\section{CDNA microarray analysis}

Total RNAs from NRCC-shScramble, NRCC-shFSTL1-1, and NRCC-shFSTL1-2 cells were extracted using Trizol Reagent (Life technologies, Carlsbad, CA, USA) and then reversely transcribed, biotin-labeled, fragmented, and hybridized to Human Genome U133 plus 2.0 chips (Affymetrix, Santa Clara, CA, USA) according to the manufacturer's instructions. All hybridized microarrays were scanned by Affymetrix GeneChip $^{\circledR}$ Scanner 3000 (Affymetrix). Raw intensities were extracted by Command Console Software 3.1 (Affymetrix). Preprocessing was then performed by MAS5 integrated in Expression Console (Affymetrix). Probe sets with low intensities and more than two absent calls were filtered. Probe set-level data was transformed into $\log 2$ scale and summarized to gene-level data by averaging the intensities of probe sets annotating to the same gene. Genes containing probe sets whose fold changes were more than two and without absent calls were considered differentially expressed genes. Gene set enrichment analysis (GSEA) was applied to explore the enriched gene sets [32]. The gene expression differences between NRCC-shFSTL1 and NRCC-shScramble cells were computed as the statistic to rank the genes in the data. Normalized enrichment score (NES) were computed for every gene set in chemical and genetic perturbation part of Molecular Signatures Database v4.0 (MsigDB v4.0, http://software. broadinstitute.org/gsea). Gene sets were randomized 1000 times to obtain false discovery rate (FDR). Gene sets with FDR of $<0.25$ were considered statistically significant. Microarray data were deposited in GEO with Accession No. GSE76948. All microarray data were analyzed using $\mathrm{R}$ programming (https://www.cran.r-project.org).

\section{qRT-PCR and Western blotting}

Total RNAs were isolated and reversely transcribed into cDNA, and subjected for qRT-PCR as previously described [9]. The primers for amplification of FSTL1, IL-6, E-cadherin, $N$-cadherin, and glyceraldehyde-3-phosphate dehydrogenase (GAPDH) as well as their amplified conditions and locations are summarized in Table 1 . Amplification efficiencies of all primers are present in Table 1, estimated based on standard curve assay as previously described [33]. Gene expression was relatively quantified using GAPDH as an internal control. qPT-PCR assays were controlled using no template controls (NTC) and "no-reverse transcription" (no-RT) controls. Quantification cycle $\left(\mathrm{C}_{\mathrm{q}}\right)$ was no less than 35 and no peak of melt curve occurred in both controls. All qPCR reactions, including reactions of NTCs and "no-RT" controls, were run in triplicate and the average $C_{q}$ of each sample was calculated based on all three biological replicates. Each qRT-PCR assay was conducted in triplicate. Protein was extracted, quantified, and subjected to Western blotting according to standard protocols as previously described [34]. The primary antibodies used in this study were as follows: anti-FSTL1 (C-term) (1:1000 dilution; Abgent No. AP10534b, San Diego, CA, USA), anti-IkB $\alpha$ (1:1000 dilution; Cell Signaling Technology No. 9242), and anti- $\beta$-actin (1:1000 dilution; Cell Signaling Technology No. 3700). $\beta$-actin was used as the loading control for cellular proteins. The protein bands were detected using GBOX Chemi XL1.4 machine (Gene, Cambridge, UK) and GeneSys version 1.2.2.0 software. The densities of protein bands were quantified using Genetools software (version 4.02, Cambridge, UK). 
Table 1 Primers and reaction conditions for the measurement of gene transcriptional levels using quantitative reverse transcription-polymerase chain reaction

\begin{tabular}{|c|c|c|c|c|c|c|}
\hline Gene & Reaction program & Forward primer $\left(5^{\prime}-3^{\prime}\right)$ & Reverse primer $\left(5^{\prime}-3^{\prime}\right)$ & $E(\%)$ & $R^{2}$ & Location \\
\hline FSTL1 & $\begin{array}{l}95^{\circ} \mathrm{C} \text { for } 3 \mathrm{~min} ; 45 \mathrm{cycles} \text { of } \\
95^{\circ} \mathrm{C} \text { for } 10 \mathrm{~s}, 60^{\circ} \mathrm{C} \text { for } 10 \mathrm{~s}, \\
\text { and } 72^{\circ} \mathrm{C} \text { for } 25 \mathrm{~s}\end{array}$ & AAATGCAGCTCCCTGTCCAA & ACTCTTGCCCTCCTCCCATAG & 95.5 & 0.999 & $\begin{array}{l}\text { Transcript: NM_007085.4 } \\
\text { Forward primer: exon } 11 \\
\text { Reverse primer: exon } 11\end{array}$ \\
\hline $\mathbb{L L}-6$ & $\begin{array}{l}95^{\circ} \mathrm{C} \text { for } 10 \mathrm{~min} ; 45 \text { cycles of } \\
95^{\circ} \mathrm{C} \text { for } 10 \mathrm{~s}, 60^{\circ} \mathrm{C} \text { for } 10 \mathrm{~s}, \\
\text { and } 72{ }^{\circ} \mathrm{C} \text { for } 25 \mathrm{~s}\end{array}$ & GCTTTAAGGAGTTCCTGC & GGTAAGCCTACACTTTCCA & 102.6 & 0.997 & $\begin{array}{l}\text { Transcript: NM_000600.4 } \\
\text { Forward primer: exon } 5 \\
\text { Reverse primer: exon } 5\end{array}$ \\
\hline$N$-cadherin & $\begin{array}{l}95^{\circ} \mathrm{C} \text { for } 3 \text { min; } 45 \text { cycles of } \\
95^{\circ} \mathrm{C} \text { for } 10 \mathrm{~s}, 60^{\circ} \mathrm{C} \text { for } 10 \mathrm{~s}, \\
\text { and } 722^{\circ} \mathrm{C} \text { for } 25 \mathrm{~s}\end{array}$ & TGGATGAAGATGGCATGG & AGGTGGCCACTGTGCTTAC & 98.6 & 0.999 & $\begin{array}{l}\text { Transcript: NM_001792.4 } \\
\text { Forward primer: exon } 3 \\
\text { Reverse primer: exon } 4\end{array}$ \\
\hline E-cadherin & $\begin{array}{l}95^{\circ} \mathrm{C} \text { for } 4 \text { min; } 40 \text { cycles of } \\
95^{\circ} \mathrm{C} \text { for } 10 \mathrm{~s} \text { and } 60^{\circ} \mathrm{C} \text { for } \\
45 \mathrm{~s}\end{array}$ & GTCATCCAACGGGAATGCA & TGATCGGTTACCGTGATCAAAA & 97.1 & 0.999 & $\begin{array}{l}\text { Transcript: NM_004360.4 } \\
\text { Forward primer: exon } 4 \\
\text { Reverse primer: exon } 5\end{array}$ \\
\hline GAPDH & $\begin{array}{l}95^{\circ} \mathrm{C} \text { for } 10 \mathrm{~min} ; 45 \text { cycles of } \\
95^{\circ} \mathrm{C} \text { for } 10 \mathrm{~s}, 60^{\circ} \mathrm{C} \text { for } 10 \mathrm{~s}, \\
\text { and } 72^{\circ} \mathrm{C} \text { for } 25 \mathrm{~s}\end{array}$ & TGACTTCAACAGCGACACCCA & CACCCTGTTGCTGTAGCCAAA & 101.5 & 0.998 & $\begin{array}{l}\text { Transcript: NM_002046.5 } \\
\text { Forward primer: exon } 6 \\
\text { Reverse primer: exon } 4\end{array}$ \\
\hline
\end{tabular}

$\mathrm{E}=$ primer efficiency; $\mathrm{R}^{2}=$ correlation coefficient

FSTL1 follistatin-like protein 1; IL-6 interleukin-6; GAPDH glyceraldehyde-3-phosphate dehydrogenase

\section{Study patients and follow-up}

Formalin-fixed paraffin-embedded specimens of surgically removed tissues were collected from Changhai Hospital Affiliated to Second Military Medical University (Shanghai, China) between December 1998 and November 2011. All specimens were pathologically confirmed as ccRCC at the enrollment. We excluded ccRCC patients who refused to be enrolled in the study and those who did not adhere to the follow-up examination. All patients enrolled in this study were re-examined at our hospital within 1 month after surgery. The follow-up examination was performed every 6 months at our outpatient clinics or through phone. The last date of follow-up was May 5, 2015. Death from ccRCC relapse was defined as an event. Patients alive at the last follow-up and died of other causes were censored. Disease-specific survival (DSS) was defined as the duration from the date of receiving surgery to the date when patient died of ccRCC or when patient received the last follow-up. This study was approved by the institutional review board of Second Military Medical University. All experiments were performed in accordance with relevant guidelines. Informed consent was obtained from all subjects.

\section{Immunohistochemistry}

Immunohistochemistry (IHC) for tumor and adjacent tissues of ccRCC patients was processed using standard techniques in our laboratory [34]. The expression levels of FSTL1 was examined in all available tumor and adjacent tissue samples. Meanwhile, hypoxia-inducible factor (HIF)- $1 \alpha$ and HIF- $2 \alpha$ were also examined in the patients with sufficient tissue samples. Rabbit polyclonal antibodies to human FSTL1 (C-term) (1:50 dilution; Abgent
No. AP10534b), anti-HIF-1 $\alpha$ (1:30 dilution; Novus Biologicals No. NB100-105 Littleton, CO, USA), and antiHIF- $2 \alpha$ antibodies (1:300 dilution; Novus Biologicals No. NB100-132) were applied according to the manufacturers' protocols. The IHC staining was analyzed by Leica microsystems (DMI3000B, Wetzlar, Germany) and LAS version 4.0.0 software. IHC scores were independently assessed by three investigators who were blind to the clinical data. Briefly, IHC score was ranked by negative $(-)$, slightly positive $(+)$, moderately positive $(++)$, and strongly positive $(+++)$ according to the extent and intensity of immunostaining. The staining extent was graded as $1(0 \%-4 \%), 2(5 \%-24 \%), 3(50 \%-74 \%)$, and 4 (> 75\%); the staining intensity was ranked by 0 (negative), 1 (weak), 2 (moderate), and 3 (strong). Values of staining intensity and extent were multiplied as the IHC score: $-(0),+(1-3),++(4-8),+++(\geq 9)$. We accessed each pathological site of the adjacent normal specimens including glomeruli, proximal convoluted tubules, distal convoluted tubules, and collecting ducts, independently, and then summed these scores as the total score of an adjacent tissue. There was an agreement on immunoreactive scores (87\%) among the investigators. Consensus was obtained after discussion.

\section{Statistical analysis}

The comparative threshold cycle (Ct) method was employed to quantify the relative change in expression of target genes. Student $t$ test was performed for two-group comparisons, and one-way ANOVA was performed for three-group comparisons. Paired Wilcoxon test was applied to evaluate the degree of positive immunostaining for FSTL1. Non-parametric analysis of 
Spearman correlation test was used to assess the correlation of the expression level of FSTL1 with that of HIF- $1 \alpha$ or HIF- $2 \alpha$. For postoperative survival analysis, DSSs and their 95\% confidence intervals (95\% CIs) were estimated by Kaplan-Meier method. The log-rank test was used to compare DSSs between groups. Proportional hazard assumption was assessed by drawing Kaplan-Meier survival curves. Multivariate Cox proportional hazards model was applied to estimate the hazard ratios (HRs) with 95\% CIs for DSSs. Age, gender, and FSTL1 staining, and American Joint Committee on Cancer (AJCC) stage were introduced into this model. Above statistical tests were two-sided and conducted using Statistical Program for Social Sciences (SPSS 20.0, Chicago, IL, USA). Data are presented as mean \pm standard error of mean (SEM) for triplicates. A $P$ value of $<0.05$ was considered statistically significant.

\section{Results}

The growth and aggressiveness of ccRCC cells with altered expression of FSTL1

qRT-PCR was applied to determine the gene expression level of FSTL1 in ccRCC cell lines (ACHN, NRCC, MRCC, and 786-O) and HEK 293T cells (Fig. 1). It was shown that FSTL1 mRNA level was significantly lower in ACHN, NRCC, and MRCC cells than in HEK 293T cells ( $P$ values were $0.022,0.004$, and 0.007 , respectively); however, FSTL1 mRNA level was significantly higher in $786-O$ cells than in HEK 293T cells $(P=0.002)$.

Retrovirus-mediated shRNA constructs targeting different regions of FSTL1 mRNA was applied to generate two stable FSTL1-knockdown cell lines termed NRCCshFSTL1-1 and NRCC-shFSTL1-2 that were derived from NRCC cells. FSTL1 mRNA level was down-regulated by approximately $80 \%$ in NRCC-shFSTL1-1 and NRCC-shFSTL1-2 cells compared with that in shScramble control NRCC cells (Fig. 2a). Altered expression of FSTL1 was confirmed on protein levels by Western blotting (Fig. 2a). We selected NRCC-shFSTL1-2 cells in subsequent cell activity and cell cycle percentage assays. FSTL1 knockdown significantly promoted anchorageindependent growth (Fig. 2b), migration (Fig. 2c), and invasion (Fig. 2d). Transient transfection of shFSTL1 significantly reduced FSTL1 transcription in 786-O and ACHN cells, resulting in significantly increased anchorage-independent growth, migration, and invasion (Fig. 2). Transient transfection of FSTL1 cDNA significantly increased FSTL1 expression in ACHN cells and only attenuated cell migration ability (Fig. 2). MRCC was resistant to the stable or transient transfection of shFSTL1.

In cell cycle assay, NRCC-shFSTL1 and NRCCshScramble cells were cultured and passaged synchronously. Flow cytometry was applied to determine cell cycle and cellular markers. It was found that the percentage of cells gated in the $\mathrm{S}$ and $\mathrm{G}_{2} / \mathrm{M}$ phases were higher in NRCC-shFSTL1 cells than in NRCC-shScramble cells $(P=0.048, P=0.011$; Fig. $3 \mathrm{a})$; the percentage of CD99positive cells was increased $(P=0.026$; Fig. $3 \mathrm{~b})$, whereas the percentage of CD24-positive cells was decreased in NRCC-shFSTL1 cells $(P=0.013$; Fig. $3 \mathrm{c})$. NRCC cells were nearly $100 \%$ positive for CD44 but almost all negative for CD133, CD105, EpCAM, and vimentin (data not shown), as measured by flow cytometry.

\section{FSTL1 knockdown up-regulated the NF-KB and HIF signaling pathways}

To explore the molecular mechanism by which FSTL1 affects the progression of ccRCC, we examined the gene expression profiles of the two NRCC-shFSTL1 cell lines with NRCC-shScramble cells using cDNA microarray assays (GEO Accession No. GSE76948). After filtered with absent/present calls, 105 differentially expressed genes with a fold change of $>2$ were identified in FSTL1 knockdown NRCC cells, including 57 up-regulated genes and 48 down-regulated genes. The spectrum and absolute gene

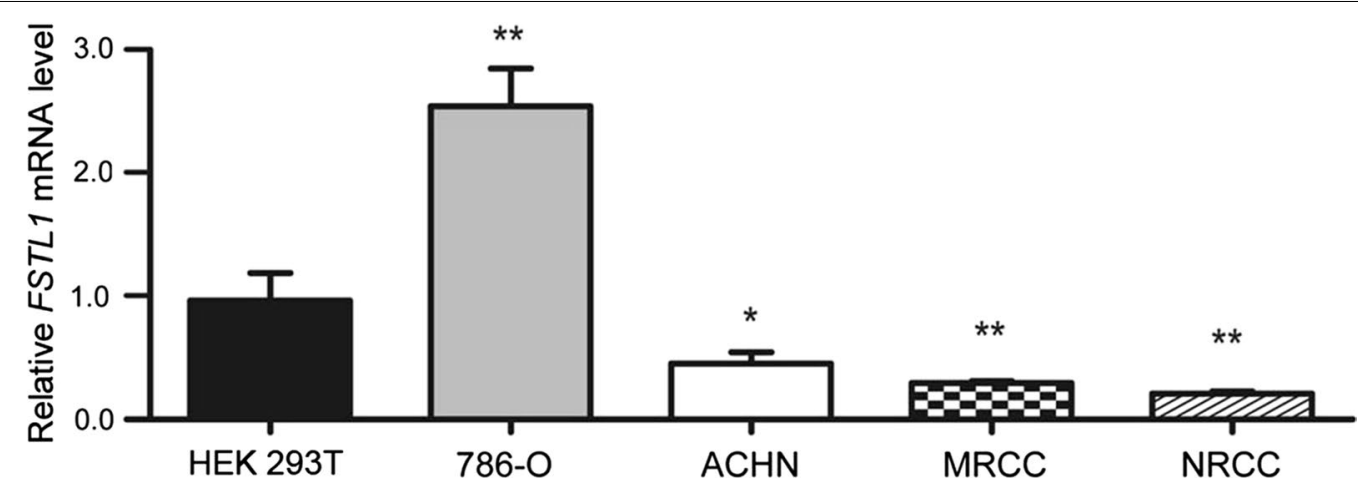

Fig. 1 Follistatin-like protein 1 (FSTL1) mRNA expression levels in clear cell renal-cell carcinoma (CCRCC) and kidney cell lines. Relative levels of FSTL1 mRNA expression in cCRCC cell lines (ACHN, NRCC, MRCC, and 786-O) and human embryonic kidney (HEK) 293T cells $\left({ }^{*} P<0.05,{ }^{* *} P<0.01\right)$ 


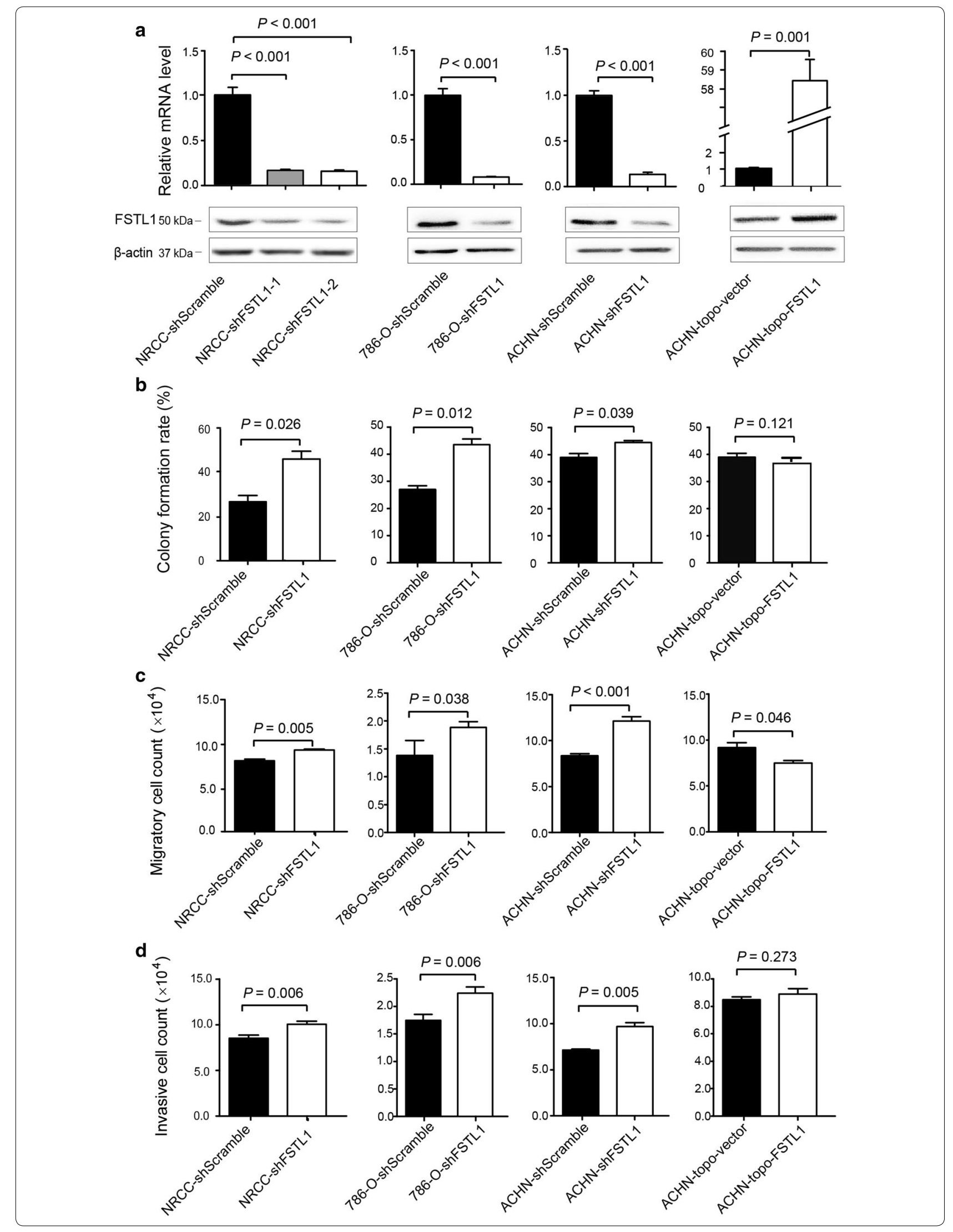


(See figure on previous page)

Fig. 2 Effects of altered FSTL1 expression on anchorage-independent growth, migration, and invasion of ccRCC cells. a Relative level of FSTL1 mRNA in the stable FSTL1 knockdown cell lines (NRCC-shFSTL1-1 and NRCC-shFSLT1-2), in cell lines with transient transfection of shFSTL1 (786-O-shFSTL1 and ACHN-shFSTL1), and in ACHN cell line transiently transfected with FSTL1 CDNA (ACHN-topo-FSTL1). b Anchorage-independent growth of ccRCC cell lines with FSTL1 knockdown and of ACHN cells transiently transfected with topo-FSTL1. c Migration of ccRCC cell lines with FSTL1 knockdown and of ACHN cells transiently transfected with topo-FSTL1. d Invasion of cCRCC cell lines with FSTL1 knockdown and of ACHN cells transiently transfected with topo-FSTL1

expression levels of differentially expressed genes identified were consistent between NRCC-shFSTL1-1 and NRCC-shFSTL1-2 cells (Fig. 4a, b). We applied GSEA software package to enrich the gene sets from the global gene expression in response to FSTL1 knockdown in NRCC cells. Taking FDR of $<25 \%$ as threshold, 12 functional gene sets were enriched by the down-regulated genes and 23 were enriched by the up-regulated genes. According to NES, the top 11 gene sets enriched by the up-regulated genes were applied to construct a network (Fig. 4c). In this network, NF-kB- and HIF-related functional gene sets formed two obvious subnetworks. The representative gene sets with the highest NES score in the NF- $\mathrm{KB}$ - and the HIF-related signaling subnetworks were named "Hinata NF-кB targets keratinocyte up" [35] and "Elvidge HIF1 $\alpha$ and HIF $2 \alpha$ targets up" [36], respectively (Fig. 4d, e).

\section{FSTL1 knockdown promoted IL-6 expression, epithelial-to-mesenchymal transition (EMT), and TNFa-induced degradation of NF-KB inhibitor (IKBa) in ccRCC cells}

Our qRT-PCR assays indicated that $I L-6$ transcription was significantly up-regulated following FSTL1 knockdown in ACHN, 786-O, and NRCC cells $(P<0.05)$ (Fig. 5a). The transcription of E-cadherin was significantly down-regulated whereas $N$-cadherin was significantly up-regulated following FSTL1 knockdown in NRCC cells; transient transfection of shFSTL1 also down-regulated E-cadherin and up-regulated $N$-cadherin in ACHN cells. Furthermore, transient transfection of FSTL1 cDNA significantly up-regulated E-cadherin and down-regulated $N$-cadherin in ACHN cells (Fig. 5b, c). We used Western blotting to analyze the expression of $\mathrm{I} \kappa \mathrm{B} \alpha$ protein in response to $\mathrm{TNF} \alpha(10 \mathrm{ng} / \mathrm{mL})$ treatment for $0,15,30,60$, and $90 \mathrm{~min}$. The relative $I_{k} B \alpha$ levels were calculated based on its baseline expression at the $0 \mathrm{~min}$ and adjusted by expression levels of $\beta$-actin. It was found that FSTL1 knockdown repressed the recovery of IкB $\alpha$ after TNF $\alpha$ treatment (Fig. 5d).

\section{Expression patterns of FSTL1, HIF-1 $a$, and HIF-2 $a$ in human cCRCC tissues and adjacent renal tissues as well as their roles in predicting postoperative prognosis}

A total of 89 ccRCC patients (men, 59; women, 30) were involved in the final analysis. The median age of the 89
ccRCC patients was 59 years (range $25-85$ years). Sixtythree $(70.8 \%)$ patients had stage I-II ccRCC. The median follow-up time was 82.3 months (interquartile range 58.8-102.2 months). All patients involved in this study had tumor tissue samples and 67 had the paired adjacent renal tissues. FSTL1 expression was examined by using IHC in all 89 tumor tissues, and 67 adjacent renal tissues. However, HIF- $1 \alpha$ and HIF- $2 \alpha$ expression was examined in only 85 and 78 tumor tissues, respectively, because some tissue specimens were insufficient for IHC assays of all target proteins. FSTL1 was positive in $65.2 \%$ (58/89) of ccRCC tissues and $94.0 \%(63 / 67)$ of the adjacent non-cancer tissues. In the adjacent tissues, FSTL1 was selectively positive in epithelial cytoplasm of the loop of Henle; HIF- $1 \alpha$ was negative whereas HIF- $2 \alpha$ was positive in the loop of Henle (Fig. $6 a-c$ ). In ccRCC tissues, FSTL1 was negative or detected in the cytoplasm of cancer cells; HIF- $1 \alpha$ and HIF- $2 \alpha$ were positive in $52.9 \%$ $(45 / 85)$ and $66.7 \%(52 / 78)$ of ccRCC cases, respectively (Fig. $6 \mathrm{~d}-\mathrm{f}$ ). The positive rate of FSTL1 protein was significantly lower in ccRCC tissues than in the adjacent normal tissues among 67 patients with paired ccRCC specimens $(P<0.001$, Table 2$)$. In ccRCC tissues, FSTL1 expression was positively correlated with HIF-1 $\alpha$ (Spearmen $r=0.216, P=0.047$ ) but negatively correlated with HIF-2 $\alpha$ expression (Spearmen $r=-0.229, P=0.044$ ) (Table 3).

A total of 89 ccRCC patients who had IHC scores of FSTL1 expression in tumor tissues were successfully followed up after surgery. Up to the date of last visit, 17 patients died of ccRCC relapse. Kaplan-Meier analysis indicated that intratumoral FSTL1 expression predicted a favorable postoperative DSS (Fig. 6g). The Kaplan-Meier survival curves for FSTL1-positive and FSTL1-negative patients were not cross, suggesting that the proportional hazards assumption was reasonable in this case. Compared with the patients with AJCC stages III-IV ccRCC, those with stages I-II diseases had a good prognosis (log-rank test, $P=0.004)$. No significant correlation was observed between intratumoral FSTL1 expression and AJCC stage of ccRCC patients (Table 3). Multivariate Cox regression analysis including age, gender, and AJCC stage showed that intratumoral FSTL1 expression conferred a favorable postoperative prognosis independently (Table 4). Moreover, Kaplan-Meier analysis showed that 


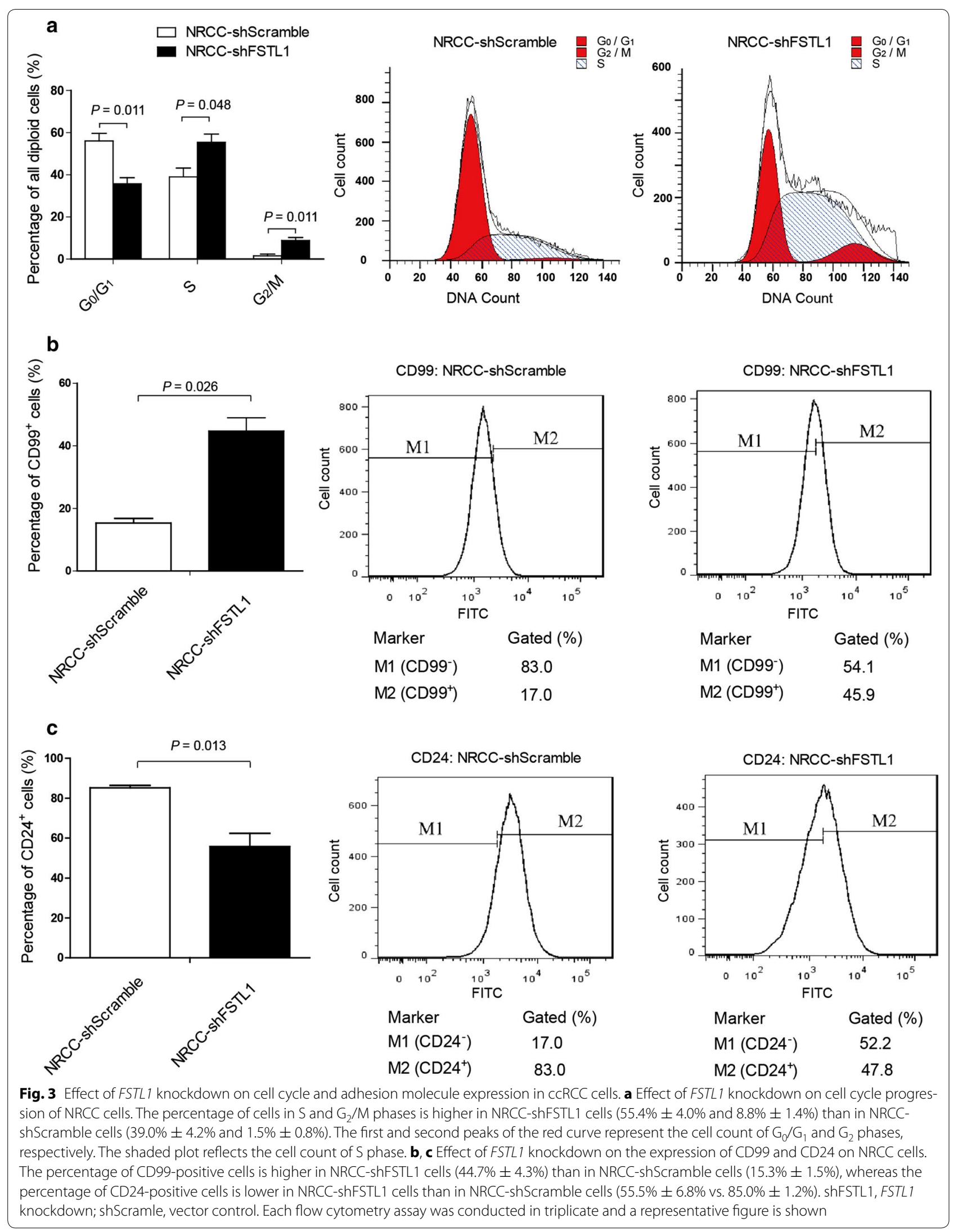


a

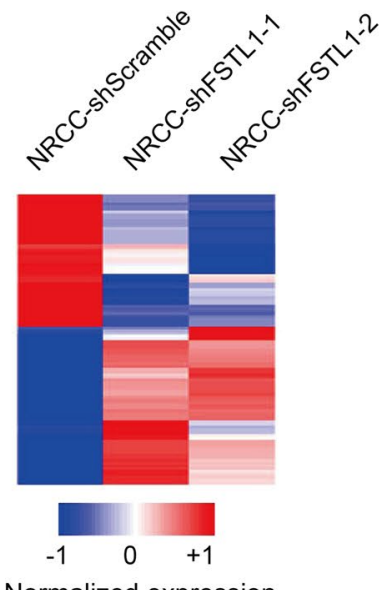

Normalized expression

b
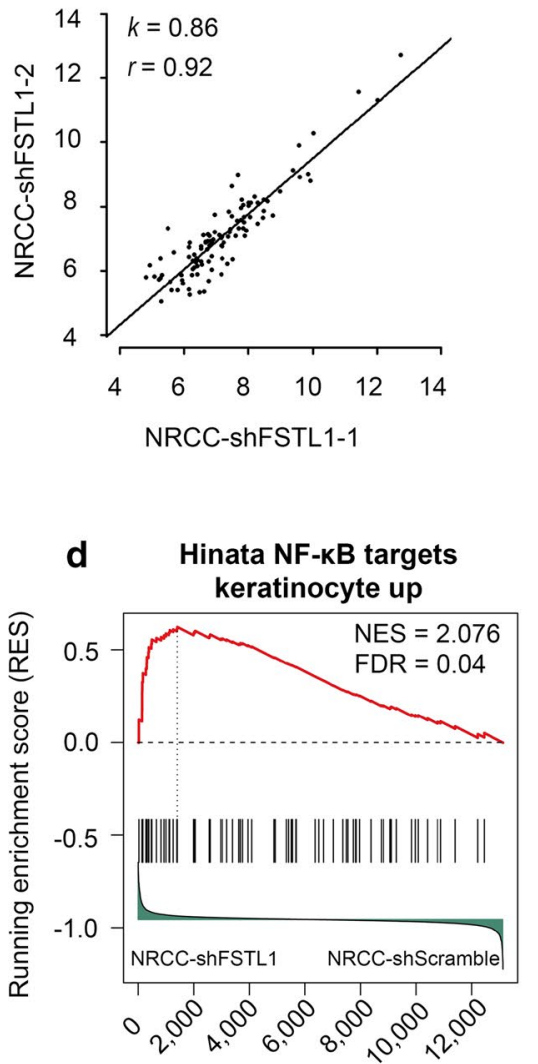

Gene list index

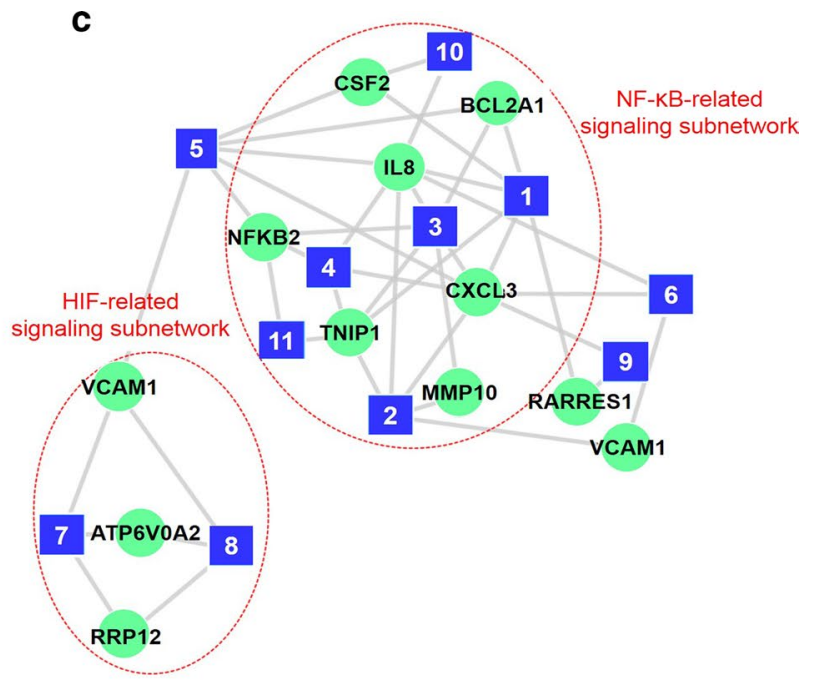

\begin{tabular}{|c|c|c|}
\hline ID & Gene sets & NES \\
\hline 1 & Hinata NF-KB targets keratinocyte up & 2.07 \\
\hline 2 & Sana TNF signaling up & 2.04 \\
\hline 3 & Zhang response to IKK Inhibitor and TNF Up & 2.02 \\
\hline 4 & Tian TNF signaling via NF-kB & 2.00 \\
\hline 5 & Senese HDAC1 targets up & 1.97 \\
\hline 6 & Mahadevan response to MP470 up & 1.95 \\
\hline 7 & Elvidge HIF $1 \alpha$ and HIF2 $\alpha$ targets up & 1.94 \\
\hline 8 & Elvidge HIF1 $\alpha$ targets up & 1.92 \\
\hline 9 & Takeda targets of NU98 HOXA9 fusion 10D dn & 1.86 \\
\hline 10 & Schoen NF-KB signaling & 1.84 \\
\hline 11 & Rashi NF-KB targets & 1.84 \\
\hline
\end{tabular}

e Elvidge HIF1 $\alpha$ and HIF2 $\alpha$

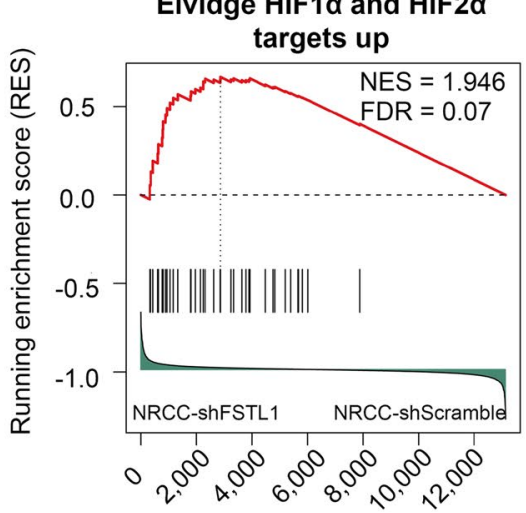

Gene list index

Fig. 4 Major signaling pathways enriched by up-regulated genes in FSTL1-knockdown ccRCC cells by microarray assay. a Heat map of 105 differentially expressed genes (48 down-regulated and 57 up-regulated). b Reproducibility of the 105 differentially expressed genes in NRCC-shFSTL1-1 and NRCC-shFSTL1-2 cells (Pearson correlation coefficient $r=0.92$; scope of linear model $k=0.86, P<0.001$ ). c Ranked by normalized enrichment score (NES), the top 11 gene sets (blue squares) enriched by up-regulated genes in response to FSTL 1 knockdown are selected to plot the network. Intersection genes (green dots) with fold change $>2$ were plotted to connect the gene sets. The gene sets fell into nuclear factor-KB (NF-KB)- and hypoxia-inducible factor (HIF)-related signaling subnetworks, respectively, which is connected by a histone deacetylase 1 (HDAC1)-related gene sets. $\mathbf{d}$ Enrichment plot of the representative gene set with the highest NES score in the NF-KB-related signaling subnetwork. e Enrichment plot of the representative gene set with the highest NES score in the HIF-related signaling subnetwork. The vertical dashed line in each plot denoted the point at which NES reached its maximum 

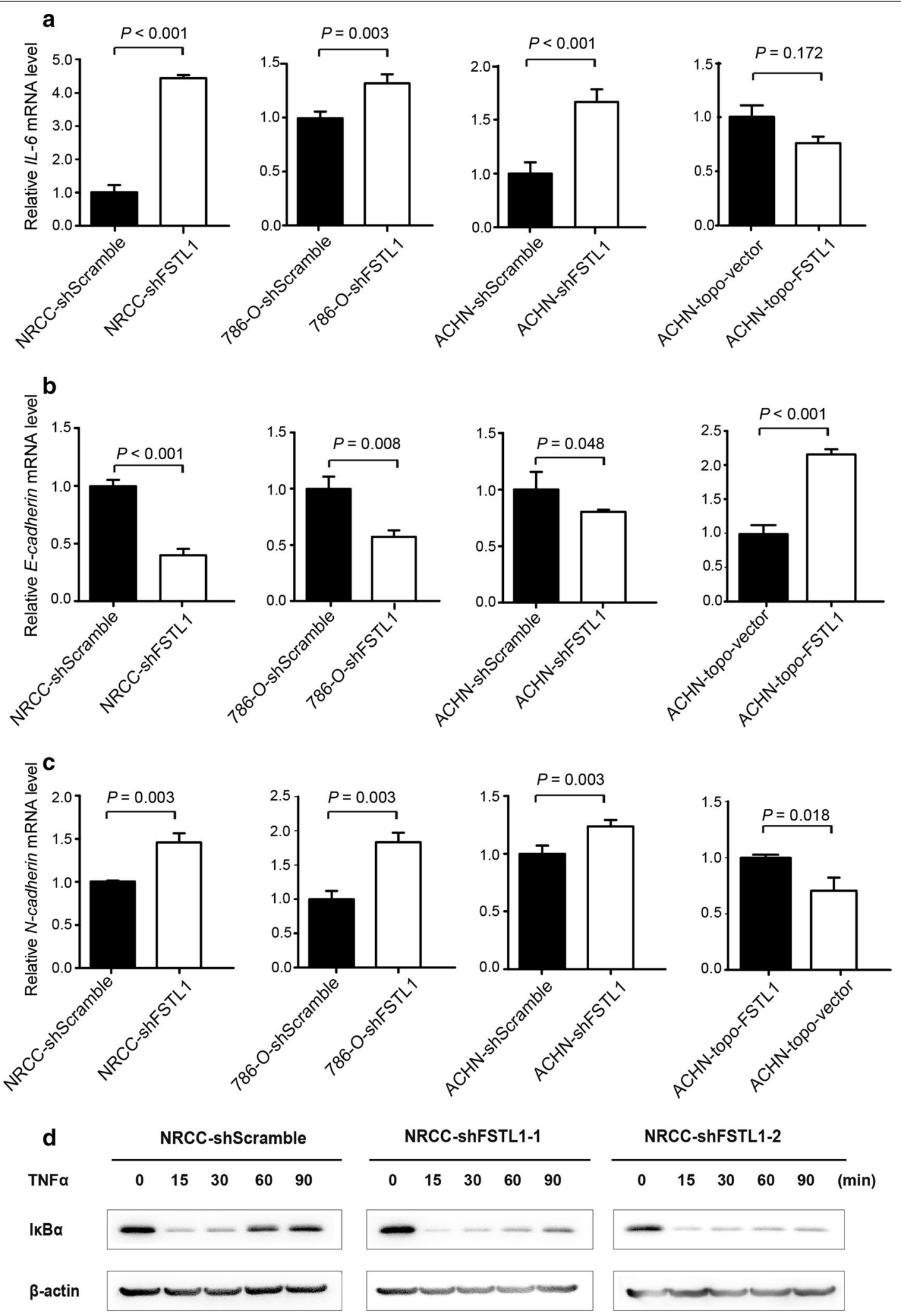

Relative $\begin{array}{lllll}100 & 21 & 26 & 52 & 78\end{array}$

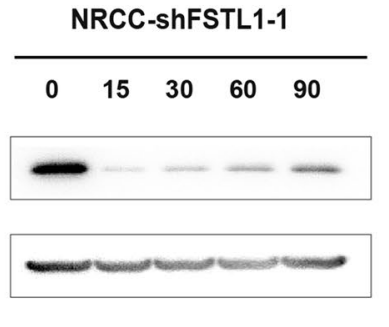

NRCC-ShFSTL1-2 expression 
(See figure on previous page)

Fig. 5 Effect of FSTL1 knockdown on epithelial-to-mesenchymal transition (EMT) and NF-KB signaling. a Levels of IL-6 mRNA in NRCC-shFSTL1, 786-O-shFSTL1, ACHN-shFSTL1, and in ACHN-topo-FSTL1. b Levels of E-cadherin mRNA in ccRCC cell lines with FSTL1 knockdown and in ACHN cells with topo-FSTL1. c Levels of N-cadherin mRNA in cCRCC cell lines with FSTL1 knockdown and in ACHN cells with topo-FSTL1. d FSTL1 knockdown speeded up the degradation of NF-KB inhibitor ( $\mathrm{IKBa}$ ) in ccRCC cells at $60 \mathrm{~min}$ following TNFa treatment. The relative expression of $\mathrm{IKBa}$ at $60 \mathrm{~min}$ is higher in NRCC-shScramble cells $(57.33 \pm 4.37, n=3)$ than in NRCC-shFSTL1-1 cells $(36.67 \pm 5.84, n=3, P=0.036)$ and NRCC-shFSTL1-2 cells $(33.67 \pm 5.04, n=3, P=0.032)$

high expression of HIF- $2 \alpha$, rather than HIF- $1 \alpha$, in tumor tissues predicted an unfavorable postoperative prognosis (Fig. 6h, i).

\section{Discussion}

In the present study, we presented a series of data to identify that FSTL1 functioned as a novel tumor suppressor in ccRCC. However, related evidence was mostly obtained from FSTL1 knockdown assays. FSTL1 knockdown facilitated ccRCC cell growth, migration, invasion, and promoted cell cycle, possibly because a low level of FSTL1 was unable to repress some cancer-promoting force(s); overexpression of FSTL1 did not inhibit the growth and invasion, possibly because FSTL1 expression at the normal level was enough to repress the cancerpromoting force(s), thus it should be important to restore the FSTL1 expression level to the normal range for attenuating the growth advantage of ccRCC. We found that MRCC and ACHN, the two cell lines derived from metastatic ccRCC tissues, were resistant to the infection with recombinant retrovirus; furthermore, MRCC was also resistant to the transient transfection, which is possibly due to the "stem-like" property of metastatic ccRCC cells [30]. Thus, we gave up our intention to up-regulate the expression of FSTL1 in MRCC. Our cytometry results indicated that FSTL1 knockdown up-regulated CD99, a cellular marker related to ccRCC aggressiveness [37], and down-regulated CD24 expression in NRCC cells. We found that CD44 was nearly $100 \%$ positive in NRCC. High CD44 expression in tumors is a poor prognostic marker of RCC [12]. CD $44^{\text {high }} \mathrm{CD} 24^{\text {low }}$ signature usually determines the cancer stem cell (CSC) and EMT phenotype in oral cancer [38]. Additionally, $\mathrm{CD} 44^{\text {high }} \mathrm{CD} 24^{\text {low }}$ signature is mostly believed to be a CSC-like phenotype in cancers such as prostate cancer [39] and breast cancer [40]. Thus, it is possible that FSTL1 knockdown increases CSC-like properties of ccRCC cells. We also found that FSTL1 knockdown promoted EMT process via up-regulating $N$-cadherin and down-regulating E-cadherin in ccRCC cells. Thus, FSTL1 might be a novel tumor suppressor that attenuates EMT process in ccRCC cells.

Using global gene expression profiling, we found NF-kB- and HIF-related functional gene sets were the predominant signaling pathways affected by FSTL1 knockdown. Interestingly, a histone deacetylase 1 (HDAC1)-related pathway bridges the NF-kB-related signaling subnetwork and HIF-related signaling subnetwork. This is supported by previous findings [41]. HDAC1 may link the NF-kB and HIF signaling pathways. The treatment with HDAC1 inhibitors might be an option of advanced RCC [42]. The two pathways work synergistically in tumor cells that survive under both inflammatory and hypoxia microenvironments. Thus, we chose to validate the activity of the NF- $\mathrm{KB}$ signaling pathway in ccRCC cells and the expression of HIF $1 / 2 \alpha$ in clinical samples. FSTL1 knockdown up-regulated the expression of $I L-6$ in ccRCC cells. Elevated level of $I L-6$ expression is associated with cancer cell proliferation, angiogenesis, and metastasis via fueling signal transducer and activator of transcription 3 (STAT3), mitogen-activated protein kinase (MAPK), and Akt signaling, thus promoting EMT and subsequent cancer metastasis [43]. FSTL1 knockdown promotes the NF-kB signaling pathway in ccRCC cells (Fig. 5d), whereas activation of NF- $k B$ promotes the development of RCC [44]. FSTL1 knockdown also affect the HIF signaling pathway. HIF- $1 \alpha$ and HIF- $2 \alpha$ have opposing effects in ccRCC biology, with HIF- $1 \alpha$ acting as a tumor suppressor and HIF- $2 \alpha$ acting as an oncogene [45]. The somatic mutation of von Hippel-Lindau $(V H L)$ gene, a tumor suppressor gene, can lead to increased expression of HIF-2 $\alpha$ in both sporadic and familial ccRCCs [46]. HIF-2 $\alpha$ activation is involved in the generation of RCC-derived, CXCR4-positive CSCs [47]. Therefore, we believe that FSTL1 knockdown may derepress NF- $\mathrm{kB}$ and HIF- $2 \alpha$ signaling in ccRCC cells, thus promoting cancer invasion and metastasis. Interestingly, both FSTL1 and HIF- $2 \alpha$ were locally expressed at the same locations but FSTL1 expression was negatively associated with HIF- $2 \alpha$ expression in ccRCC tissues, implying that FSTL1 in situ inhibit HIF- $2 \alpha$ expression in renal tissues. The mechanisms by which FSTL1 in situ inhibit HIF- $2 \alpha$ expression remains to be elucidated.

Our IHC analyses indicated that FSTL1 was locally expressed in epithelial cytoplasm in the loop of Henle, which is consistent with the results of a previous study [32]. However, it is mainly expressed in epithelial cells, rather than in mesenchymal cells as previously believed [22], indicating that the role of FSTL1 in renal tissues is 


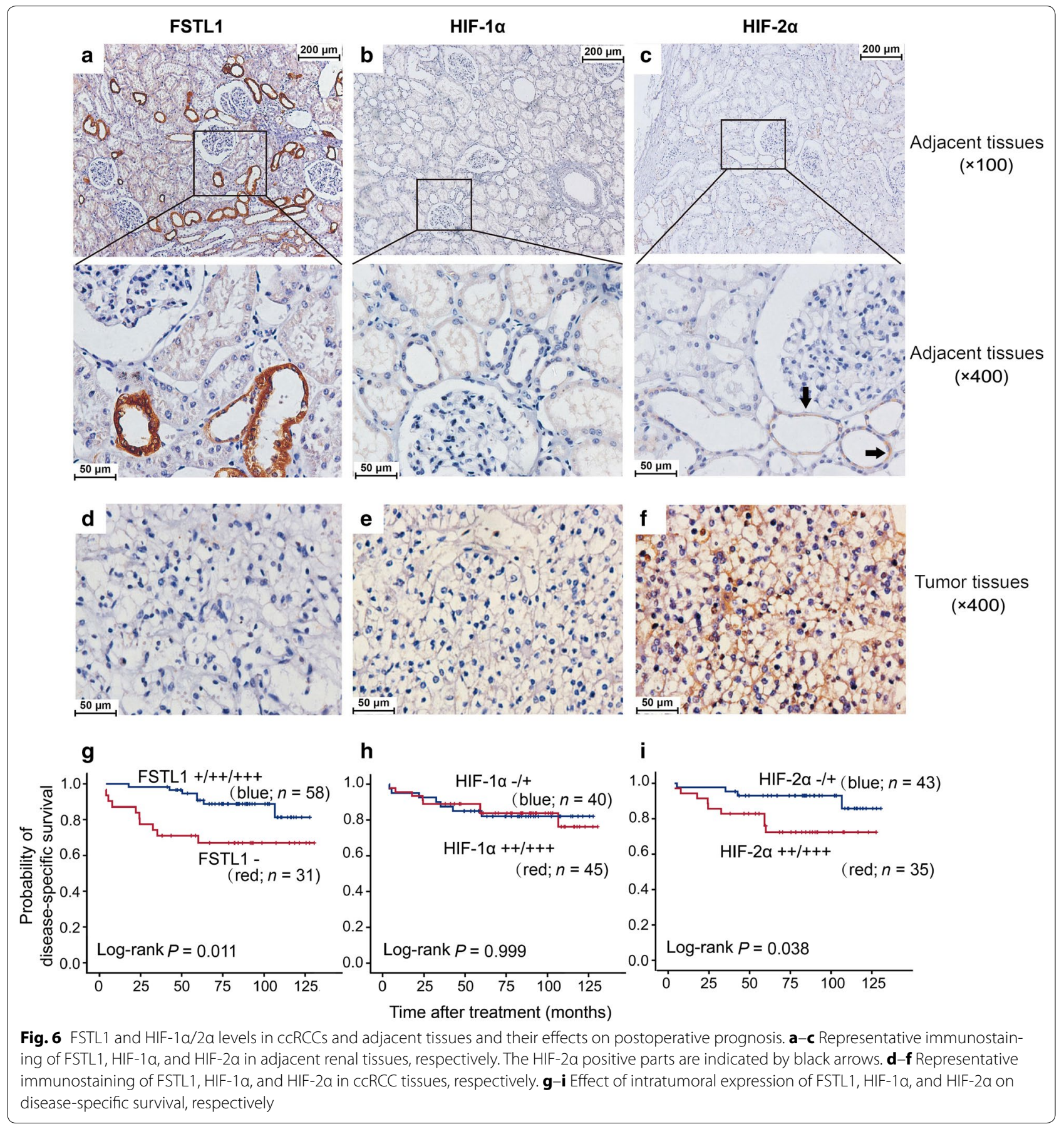

Table 2 Comparison of FSTL1 expression between tumor and paired adjacent tissues of 67 patients with clear-cell renal cell carcinoma

\begin{tabular}{lcccccc}
\hline Tissue type & \multicolumn{2}{l}{ Immunoreactive scores of FSTL1 [cases (\%)] } & & Mean rank & \\
\cline { 2 - 5 } & - & + & ++ & +++ & & \\
\hline Cancer tissues & $28(41.8)$ & $29(43.3)$ & $4(6.0)$ & $6(9.0)$ & 49.50 & $<0.001$ \\
Paired normal tissues & $4(6.0)$ & $25(37.3)$ & $20(29.9)$ & $18(26.9)$ & 85.50 & - \\
\hline
\end{tabular}


Table 3 The correlation of FSTL1 level with the expression of HIF-1a/2a in CCRCC tissues and tumor stage

\begin{tabular}{llcll}
\hline Variable & \multicolumn{2}{l}{$\begin{array}{l}\text { Immunoreactive } \\
\text { scores of FSTL1 (cases) }\end{array}$} & $P$ & $\boldsymbol{r}_{\boldsymbol{s}}$ \\
\cline { 2 - 4 } & Negative & Positive & & \\
\hline HIF-1a expression & & & & \\
Negative (-) & 19 & 21 & 0.047 & 0.216 \\
Positive (+/++/+++) & 12 & 33 & & \\
HIF-2a expression & & & & \\
Negative (-) & 5 & 21 & 0.044 & -0.229 \\
Positive (+/++/+++) & 22 & 30 & & \\
AJCC stage & & & & \\
I & 16 & 39 & 0.110 & -0.170 \\
II & 3 & 5 & & \\
III & 6 & 9 & & \\
IV & 6 & 5 & & \\
\hline
\end{tabular}

cCRCC clear-cell renal cell carcinoma; FSTL1 follistatin-like protein 1; HIF hypoxiainducible factor; $A J C C$ American Joint Committee on Cancer; $r_{s}$ Spearman rank correlation coefficient

Table 4 Factors predicting disease-specific survival of ccRCC patients in multivariate Cox proportional hazards model

\begin{tabular}{|c|c|c|}
\hline Variable & HR $(95 \% \mathrm{Cl})$ & $P$ \\
\hline Age ( $\leq 59$ vs. $>59$ years) & $0.992(0.953-1.033)$ & 0.696 \\
\hline Gender (male vs. female) & $1.337(0.470-3.802)$ & 0.585 \\
\hline AJCC stage (III-IV vs. I-II) & 3.704 (1.376-9.974) & 0.010 \\
\hline FSTL1 (positive vs. negative) & $0.325(0.118-0.894)$ & 0.030 \\
\hline
\end{tabular}

AJCC American Joint Committee on Cancer; FSTL1 follistatin-like protein 1; HR hazard ratio; $c C R C C$ clear-cell renal cell carcinoma

quite special. FSTL1 expression is significantly lower in ccRCC than in adjacent renal tissues, but the intratumoral FSTL1 expression is not associated with tumor stage. Importantly, intratumoral FSTL1 expression confers a favorable independent postoperative prognosis in ccRCC; whereas high expression of HIF-2 $\alpha$, rather than HIF- $1 \alpha$, in ccRCC tissues predicts a poor postoperative prognosis. Thus, intratumoral FSTL1 and HIF-2 $\alpha$ expression are both prognostic factors for ccRCC; however, they have inverse effects.

Our study has limitations. First, the cancer inhibition effect of FSTL1 was investigated only in vitro. The evidence generated from animal experiments are needed to further clarify the function of FSTL1 on the growth and metastatic potential of ccRCC cells. Second, only 89 patients were enrolled in this study. The value of FSTL1 for prognosis prediction remains to be re-confirmed in large cohorts.

\section{Conclusions}

This present study clarifies the important nature of FSTL1 in ccRCC. FSTL1 functions as a tumor suppressor possibly via repressing NF- $\mathrm{kB}$ and HIF- $2 \alpha$ signaling pathways. Intratumoral FSTL1 expression in ccRCC tissues conferred a favorable independent postoperative prognosis to ccRCC patients. Treatment approaches that increasing FSTL1 expression in tumors might lead to effective therapy for advanced ccRCC.

\begin{abstract}
Abbreviations
FSTL1: follistatin-like protein 1; RCC: renal cell carcinoma; cCRCC: clear cell RCC; HIF: hypoxia-inducible factor; IKBa: inhibitor of NF-KB; CXCR8: chemokine (C-X-C motif) receptor 8; CXCL16: chemokine (C-X-C motif) ligand 16; IL-6: interleukin-6; TNFa: tumor necrosis factor-a; CRC: colorectal cancer; FBS: fetal bovine serum; GAPDH: glyceraldehyde-3-phosphate dehydrogenase; IHC: immunohistochemistry; HRs: hazard ratios; Cls: confidence intervals; HEK 293T: human embryonic kidney 293T cells; shRNA: short hairpin RNA; GSEA: gene set enrichment analysis; FDRs: false discovery rates; NES: normalized enrichment scores; EMT: epithelial-to-mesenchymal transition; AJCC: American Joint Committee on Cancer; DSS: disease-specific survival; CSC: cancer stem cell; HDAC1: histone deacetylase 1; STAT3: signal transducer and activator of transcription 3; MAPK: mitogen-activated protein kinase; VHL: von Hippel-Lindau gene.
\end{abstract}

\section{Authors' contributions}

$Y L, X T, X C$, and WL contributed to acquisition of whole data independently and presented the same results. YY, YL, XT, and XH were responsible for pathological and immunohistochemical assays. JH, DS, and LW were involved in the diagnosis and the recruitment of the patients in our affiliated hospitals and follow-up study. HZ, JY, YD, and WL contributed to statistical analysis and data interpretation. TT contributed to revising it critically for important intellectual content. GC and XT designed and organized the study. GC wrote the manuscript. All authors read and approved the final manuscript.

\section{Author details}

${ }^{1}$ Department of Epidemiology, Second Military Medical University, Shanghai 200433, P. R. China. ${ }^{2}$ Department of Urology, Changhai Hospital, Second Military Medical University, Shanghai 200433, P. R. China. ${ }^{3}$ Department of Pathology, Changhai Hospital, Second Military Medical University, Shanghai 200433, P. R. China. ${ }^{4}$ Genitourinary Medical Oncology-Research, University of Texas MD Anderson Cancer Center, Houston, TX 77030, USA.

\section{Acknowledgements}

Authors thank Drs. Wei Guan and Rui Pu for their great help in the follow-up study.

\section{Competing interests}

The authors declare that they have no competing interests.

\section{Availability of data and materials}

The microarray dataset generated during this study is available in GEO with Accession No. GSE76948 [https://www.ncbi.nlm.nih.gov/geo/query/acc. cgi?acc=GSE76948]. All the other data generated and analyzed during this study are available from the corresponding author on reasonable request.

Consent for publication

Not applicable.

\section{Ethics approval and consent to participate}

The study protocol conformed to the 1975 Declaration of Helsinki and all experiments involving human tissues and clinical data were performed in accordance with relevant guidelines. Informed consent was obtained from all subjects. This study was approved by the institutional review board of Second Military Medical University. 


\section{Funding}

This work was supported by the National Key Basic Research Program (973 program) (2015CB554000 to GC), the National Natural Science Foundation of China (81520108021 and 91529305 to G.C., 81672518 and 81101928 to X.T.), and the Three-year Action Plan on Public Health, Phase IV, Shanghai, China (15GWZK0801 to GC).

Received: 23 April 2017 Accepted: 5 January 2018

Published online: 22 January 2018

\section{References}

1. Chen $W$, Zheng $R$, Zeng $H$, Zhang S. The incidence and mortality of major cancers in China, 2012. Chin J Cancer. 2016;35:73.

2. Capitanio U, Montorsi F. Renal cancer. Lancet. 2016;387:894-906.

3. Zhang ZL, Li YH, Xiong YH, Hou GL, Yao K, Dong P, et al. Oncological outcome of surgical treatment in 336 patients with renal cell carcinoma. Chin J Cancer. 2010;29:995-9.

4. Wagstaff J, Jones R, Hawkins R, Porfiri E, Pickering L, Bahl A, et al. Treatment patterns and clinical outcomes in patients with renal cell carcinoma in the UK: insights from the RECCORD registry. Ann Oncol. 2016;27:159-65

5. Woo SM, Min KJ, Chae IG, Chun KS, Kwon TK. Silymarin suppresses the PGE2 -induced cell migration through inhibition of EP2 activation; G protein-dependent PKA-CREB and G protein-independent Src-STAT3 signal pathways. Mol Carcinog. 2015;54:216-28.

6. Escudier B, Michaelson MD, Motzer RJ, Hutson TE, Clark Jl, Lim HY, et al. Axitinib versus sorafenib in advanced renal cell carcinoma: subanalyses by prior therapy from a randomised phase III trial. Br J Cancer. 2014:110:2821-8.

7. Sircar K, Rao P, Jonasch E, Monzon FA, Tamboli P. Contemporary approach to diagnosis and classification of renal cell carcinoma with mixed histologic features. Chin J Cancer. 2013;32:303-11.

8. Li X, Tan X, Yu Y, Chen H, Chang W, Hou J, et al. D9S168 microsatellite alteration predicts a poor prognosis in patients with clear cell renal cell carcinoma and correlates with the down-regulation of protein tyrosine phosphatase receptor delta. Cancer. 2011;117:4201-11.

9. Jensen HK, Donskov F, Marcussen N, Nordsmark M, Lundbeck F, von der Maase H. Presence of intratumoral neutrophils is an independent prognostic factor in localized renal cell carcinoma. J Clin Oncol. 2009:27:4709-17.

10. Fu Q, Chang Y, Zhou L, An H, Zhu Y, Xu L, et al. Positive intratumoral chemokine (C-C motif) receptor 8 expression predicts high recurrence risk of post-operation clear-cell renal cell carcinoma patients. Oncotarget. 2016;7:8413-21.

11. Li X, Ma X, Chen L, Gu L, Zhang Y, Zhang F, et al. Prognostic value of CD44 expression in renal cell carcinoma: a systematic review and meta-analysis. Sci Rep. 2015;5:13157.

12. Crispen PL, Boorjian SA, Lohse CM, Leibovich BC, Kwon ED. Predicting disease progression after nephrectomy for localized renal cell carcinoma: the utility of prognostic models and molecular biomarkers. Cancer. 2008:113:450-60

13. Lucarelli G, Galleggiante V, Rutigliano M, Sanguedolce F, Cagiano S, Bufo P, et al. Metabolomic profile of glycolysis and the pentose phosphate pathway identifies the central role of glucose-6-phosphate dehydrogenase in clear cell-renal cell carcinoma. Oncotarget. 2015;6:13371-86.

14. de Martino M, Taus C, Lucca I, Hofbauer SL, Haitel A, Shariat SF, et al. Association of human telomerase reverse transcriptase gene polymorphisms, serum levels, and telomere length with renal cell carcinoma risk and pathology. Mol Carcinog. 2016;55:1458-66.

15. Bigot P, Lughezzani G, Karakiewicz P, Perrotte P, Rioux-Leclercq N, CatrosQuemener $V$, et al. The prognostic value of erythrocyte polyamine in the post-nephrectomy stratification of renal cell carcinoma specific mortality. J Urol. 2010;183:486-91.

16. Vasudev NS, Sim S, Cairns DA, Ferguson RE, Craven RA, Stanley A, et al. Pre-operative urinary cathepsin $\mathrm{D}$ is associated with survival in patients with renal cell carcinoma. Br J Cancer. 2009;101:1175-82.

17. Fu Q, Chang Y, An H, Fu H, Zhu Y, Xu L, et al. Prognostic value of interleukin-6 and interleukin-6 receptor in organ-confined clear-cell renal cell carcinoma: a 5-year conditional cancer-specific survival analysis. Br J Cancer. 2015;113:1581-9.

18. Gutwein P, Schramme A, Sinke N, Abdel-Bakky MS, Voss B, Obermüller N, et al. Tumoural CXCL16 expression is a novel prognostic marker of longer survival times in renal cell cancer patients. Eur J Cancer. 2009;45:478-89.

19. Tan X, Zhai Y, Chang W, Hou J, He S, Lin L, et al. Global analysis of metastasis-associated gene expression in primary cultures from clinical specimens of clear-cell renal-cell carcinoma. Int J Cancer. 2008;123:1080-8.

20. Liu Y, Han X, Yu Y, Ding Y, Ni C, Liu W, et al. A genetic polymorphism affects the risk and prognosis of renal cell carcinoma: association with follistatinlike protein 1 expression. Sci Rep. 2016;6:26689.

21. Chaly Y, Hostager B, Smith S, Hirsch R. Follistatin-like protein 1 and its role in inflammation and inflammatory diseases. Immunol Res. 2014;59:266-72.

22. Wilson DC, Marinov AD, Blair HC, Bushnell DS, Thompson SD, Chaly Y, et al. Follistatin-like protein 1 is a mesenchyme-derived inflammatory protein and may represent a biomarker for systemic-onset juvenile rheumatoid arthritis. Arth rheum. 2010;62:2510-6.

23. Wei K, Serpooshan V, Hurtado C, Diez-Cuñado M, Zhao M, Maruyama S, et al. Epicardial FSTL1 reconstitution regenerates the adult mammalian heart. Nature. 2015:525:479-85.

24. Hayakawa S, Ohashi K, Shibata R, Kataoka Y, Miyabe M, Enomoto T, et al. Cardiac myocyte-derived follistatin-like 1 prevents renal injury in a subtotal nephrectomy model. J Am Soc Nephrol. 2015;26:636-46.

25. Kudo-Saito C, Fuwa T, Murakami K, Kawakami Y. Targeting FSTL1 prevents tumor bone metastasis and consequent immune dysfunction. Cancer Res. 2013;73:6185-93.

26. Su S, Parris AB, Grossman G, Mohler JL, Wang Z, Wilson EM. Up-regulation of follistatin-like 1 by the androgen receptor and melanoma antigen-A11 in prostate cancer. Prostate. 2017:77:505-16.

27. Torres S, Bartolome RA, Mendes M, Barderas R, Fernandez-Aceñero MJ, Peláez-García A, et al. Proteome profiling of cancer-associated fibroblasts identifies novel proinflammatory signatures and prognostic markers for colorectal cancer. Clin Cancer Res. 2013;19:6006-19.

28. Chen SX, Xu XE, Wang XQ, Cui SJ, Xu LL, Jiang YH, et al. Identification of colonic fibroblast secretomes reveals secretory factors regulating colon cancer cell proliferation. J Proteomics. 2014;110:155-71.

29. Chan QK, Ngan HY, Ip PP, Liu VW, Xue WC, Cheung AN. Tumor suppressor effect of follistatin-like 1 in ovarian and endometrial carcinogenesis: a differential expression and functional analysis. Carcinogenesis. 2009:30:114-21.

30. Tan X, He S, Han Y, Yu Y, Xiao J, Xu D, et al. Establishment and characterization of clear cell renal cell carcinoma cell lines with different metastatic potential from Chinese patients. Cancer Cell Int. 2013;13:20.

31. Sun W, Tan X, Shi Y, Xu G, Mao R, Gu X, et al. USP11 negatively regulates TNFalpha-induced NF-kappaB activation by targeting on IkappaBalpha. Cell Signal. 2010;22:386-94.

32. Subramanian A, Tamayo P, Mootha VK, Mukherjee S, Ebert BL, Gillette MA, et al. Gene set enrichment analysis: a knowledge-based approach for interpreting genome-wide expression profiles. Proc Natl Acad Sci USA. 2005;102:15545-50.

33. Bustin SA, Benes V, Garson JA, Hellemans J, Huggett J, Kubista M, Mueller $R$, et al. The MIQE guidelines: minimum information for publication of quantitative real-time PCR experiments. Clin Chem. 2009;55:611-22.

34. Tan X, Wang Y, Han Y, Chang W, Su T, Hou J, et al. Genetic variation in the GSTM3 promoter confer risk and prognosis of renal cell carcinoma by reducing gene expression. Br J Cancer. 2013;109:3105-15.

35. Hinata K, Gervin AM, Jennifer Zhang Y, Khavari PA. Divergent gene regulation and growth effects by NF-KB in epithelial and mesenchymal cells of human skin. Oncogene. 2003;22:1955-64.

36. Elvidge GP, Glenny L, Appelhoff RJ, Ratcliffe PJ, Ragoussis J, Gleadle JM. Concordant regulation of gene expression by hypoxia and 2-oxoglutarate-dependent dioxygenase inhibition: the role of HIF-1a, HIF-2a, and other pathways. J Biol Chem. 2006;281:15215-26.

37. Lin L, Wu Q, Chang W, Chang WJ, Hou JG, Zhang HW, Tan XJ, et al. Identification of metastasis-associated alternatively spliced variants of CD99 in clear cell renal cell carcinoma tissues. Acad J Second Mili Med Univ. 2009;30:355-9 [in Chinese].

38. Ghuwalewala S, Ghatak D, Das P, Dey S, Sarkar S, Alam N, et al. $\mathrm{CD} 44^{\text {high }} \mathrm{CD} 24^{\text {low }}$ molecular signature determines the cancer stem cell and EMT phenotype in oral squamous cell carcinoma. Stem cell Res. 2016;16:405-17. 
39. Hurt EM, Kawasaki BT, Klarmann GJ, Thomas SB, Farrar WL. CD44+ CD24(-) prostate cells are early cancer progenitor/stem cells that provide a model for patients with poor prognosis. Br J Cancer. 2008;98:756-65.

40. D'Amico L, Patane S, Grange C, Bussolati B, Isella C, Fontani L, et al. Primary breast cancer stem-like cells metastasise to bone, switch phenotype and acquire a bone tropism signature. Br J Cancer. 2013;108:2525-36.

41. Yoo YG, Kong G, Lee MO. Metastasis-associated protein 1 enhances stability of hypoxia-inducible factor-1 a protein by recruiting histone deacetylase 1. EMBO J. 2006;25:1231-41.

42. Juengel E, Nowaz S, Makarevi J, Natsheh I, Werner I, Nelson K, et al. HDACinhibition counteracts everolimus resistance in renal cell carcinoma in vitro by diminishing cdk2 and cyclin A. Mol Cancer. 2014;13:152.

43. Bharti R, Dey G, Mandal M. Cancer development, chemoresistance, epithelial to mesenchymal transition and stem cells: a snapshot of IL-6 mediated involvement. Cancer Lett. 2016;375:51-61.
44. Sourbier C, Danilin S, Lindner V, Steger J, Rothhut S, Meyer N, et al. Targeting the nuclear factor- $\mathrm{kB}$ rescue pathway has promising future in human renal cell carcinoma therapy. Cancer Res. 2007;67:11668-76.

45. Schodel J, Grampp S, Maher ER, Moch H, Ratcliffe PJ, Russo P, et al. Hypoxia, hypoxia-inducible transcription factors, and renal cancer. Eur Urol. 2016:69:646-57.

46. Cancer Genome Atlas Research Network. Comprehensive molecular characterization of clear cell renal cell carcinoma. Nature. 2013;499:43-9.

47. Micucci C, Matacchione G, Valli D, Orciari S, Catalano A. HIF2a is involved in the expansion of CXCR4-positive cancer stem-like cells in renal cell carcinoma. Br J Cancer. 2015;113:1178-85.

\section{Submit your next manuscript to BioMed Central and we will help you at every step:}

- We accept pre-submission inquiries

- Our selector tool helps you to find the most relevant journal

- We provide round the clock customer support

- Convenient online submission

- Thorough peer review

- Inclusion in PubMed and all major indexing services

- Maximum visibility for your research

Submit your manuscript at www.biomedcentral com/submit 